\title{
Farklı Çay Türleri ile Hazırlanan Kombuchaların Biyoaktif ve Duyusal Özelliklerinin Belirlenmesi
}

\author{
Selin KALKAN ${ }^{1 *} \mathbb{D}$, Mustafa Remzi OTAĞ $\breve{G}^{1}$, Sümeyye SARMUSAK ${ }^{1}{ }^{\mathbb{D}}$, Feride Buse \\ GÖNÜLTAŞ ${ }^{1}$ iD, Arife YAŞAR ${ }^{1} \odot$
}

${ }^{1} 1$ Giresun Üniversitesi, Mühendislik Fakültesi, Gıda Mühendisliği Bölümü, Giresun, 28200, Türkiye

Geliş / Received: 11/05/2019, Kabul / Accepted: 20/02/2020

\section{Öz}

Kombucha çayı, çeşitli bakteri ve mayaların simbiyotik birlikteliğinden oluşan, Kombucha mantarı ile elde edilen hafif ekşimsi-tatlı lezzete sahip fermente bir içecektir. Bu çalışmada siyah, beyaz ve yeşil çaylardan üretilen fermente Kombuchaların antimikrobiyel, antioksidan etkileri ile duyusal özelliklerinin belirlenmesi amaçlanmıştır. Çay örneklerinin antimikrobiyel etkilerinin belirlenmesinde disk difüzyon yöntemi kullanılmış olup, seçilmiş insan ve gıda kaynaklı patojen test mikroorganizmalarına karşı antimikrobiyel etki tespit edilmiştir. Örneklerin antioksidan etkilerinin belirlenmesinde iki farklı yöntem kullanılmış olup, ABTS ve DPPH radikal süpürme kapasiteleri ölçülmüştür. Kombucha çaylarının duyusal analizlerinde, örneklerin aroma, lezzet, parlaklık, dem rengi, burukluk ve genel beğenilirlik özellikleri değerlendirilmiştir. Sonuç olarak, yeşil

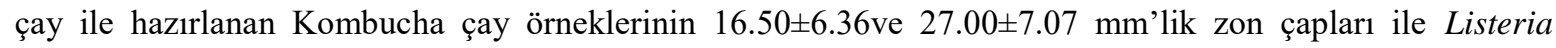
monocytogenes'e karşı en yüksek antimikrobiyel aktiviteyi gösterdikleri tespit edilmiştir. Antioksidan aktiviteleri açısından çay örnekleri değerlendirildiğinde, siyah, beyaz ve yeşil çay örneklerine kıyasla Kombucha mantarı ile fermente edilerek hazırlanan çay örneklerinin antioksidan özelliklerinin arttı̆̆ belirlenmiştir. Duyusal analizler sonucunda ise en beğenilerek tüketilen ve duyusal özellikler açısından tercih edilen Kombucha çayının ise siyah çay kullanılarak hazırlanan örnekler olduğu bildirilmiştir.

Anahtar Kelimeler: Kombucha çayı, antioksidan, antimikrobiyel, duyusal özellikler

\section{Determination of Bioactive and Sensory Properties of Kombucha Produced With Different Tea Types}

\begin{abstract}
Kombucha tea is a fermented beverage with a mild sourish-sweet taste obtained by Kombucha mushroom consisting of the symbiotic combination of various bacteria and yeasts. In this study, it was aimed to determine the antimicrobial, antioxidant effects and sensory properties of the fermented Kombucha tea samples produced from black, white and green teas. Disc diffusion method was used to determine the antimicrobial effects of tea samples and the antimicrobial effect was determined against selected human and foodborne pathogenic bacteria. Two different methods were used to determine the antioxidant effects of the samples and ABTS and DPPH radical scavenging capacities were measured. For sensory analysis of Kombucha teas, the aroma, flavor, brightness, color of steep, sourness and general approval characteristics of the samples were evaluated. As a result, it was determined that Kombucha tea samples prepared with green tea showed the highest antimicrobial activity against Listeria monocytogenes with $16.50 \pm 6.36$ and $27.00 \pm 7.07 \mathrm{~mm}$ zone diameters. When the tea samples were evaluated in terms of antioxidant activities, it was established that the antioxidant properties of the tea samples prepared by the fermented Kombucha mushroom were increased compared to the black, white and green tea samples. As a conclusion of sensory analyzes, it was determined that Kombucha tea prepared using black tea was the most liked and consumed, preferred in terms of sensory properties.
\end{abstract}

Keywords: Kombucha tea, antioxidant, antimicrobial, sensory properties

*Sorumlu Yazar: selin.kalkan@giresun.edu.tr 


\section{Giriş}

Japonca'da ''Kombu' bir deniz yosunu olan Laminaria japonica'yı tanımlamakta 'Cha' ise çay anlamına gelmektedir (El-Taher, 2011). Kombucha, tatlandırılmış demlenmiş çayın, maya ve asetik asit bakteri kültürü karışımıyla fermantasyonu ile elde edilen, hafif, tatlı ekşi aromalı bir çay içeceğidir (Aidoo vd., 2006). Kombucha kuzeydoğu Çin'den (eski Mançurya bölgesi) doğmuş, daha sonra Rusya'ya ve dünyanın geri kalanına yayılmıştır. Kombucha, tatlandırılmış siyah çayın, yaklaşık 14 gün boyunca oda sıcaklığında "çay mantarı" olarak bilinen popüler bir kültürle mayalayarak hazırlanması ile elde edilir (Anken ve Kappel, 1992). Bu içeceğin, artrit, sedef hastalığı, kabızlık, hazımsızlık ve hipertansiyon gibi çok sayıda metabolik hastalıklara karşı yararı olduğu bildirilmekte, ancak etkinliği için henüz mevcut çok az bilimsel kanıt bulunmaktadır. Bildirilen sağlığ1 teşvik eden birçok yönüyle ve bu içecek evde kolay ve güvenli bir şekilde hazırlanabiliyor olması nedeniyle, geleneksel bir içecek olarak popülerlik kazanmıştır (Dufresne ve Farnworth, 2000; Ernst, 2003; Greenwalt vd., 2000; Hartmann vd., 2000; Ram vd., 2000; Pauline vd., 2001).

Kombuchaların üretiminde kullanılan "çay mantarı" aslında maya ve asetik bakterilerin bir simbiyozudur (Kappel ve Anken, 1993; Steinkraus vd., 1996). Çay mantarında bulunan ana asetik asit bakterileri, Acetobacter xylinum (Balentine, 1997), Acetobacter xylinoides, Bacterium gluconicum (Reiss, 1994), Acetobacter aceti, Acetobacter pasteurianus'dur (Liu vd., 1996). Fermente edilmiş Kombucha çaylarında tanımlanan mayalar ise Schizosaccharomyces pombe, Saccharomycodes ludwigii, Kloeckera apiculata, Saccharomyces cerevisiae, Zygosaccharomyces bailii, Torulaspotandel brueckii, Brettanomyces bruxelltan'dir. Ayrica Candida ve Pichia türleri de çay mantarından izole edilmiştir (Jankovicve Stojanovic, 1994; Balentine, 1997; Liu vd., 1996; Mayser vd., 1995; Teoh vd., 2004). Çayın mikrobiyolojik bileşimi, mevcut mikroorganizmaların çay fermantasyonu sirasındaki inokülum düzeylerine bağlıdır. Kombucha' nın fermantasyon sürecinde bu mikroorganizmaların büyüme düzenleri net bir şekilde aydınlatılamamıştır. Fermantasyon sirasinda $A$. xylinum tarafindan üretilen selüloz, şekerli çay üzerinde, bakteri ve mayaların hücre kütlesinin bağlı olduğu ince bir film halinde görünür. Bu mantar benzeri mikroorganizma ve selüloz karışımı, Kombucha'nın "çay mantarı" olarak da adlandırılmasının olası bir nedenidir (BauerPetrovska ve Petrushevska-Tozi, 2000).

Her ne kadar yeşil çay Kombucha'nın hazırlanmasında kullanılabilirse de, bu içeceğin antimikrobiyal aktivitesi üzerine yapılan çalışmaların çoğu, en iyi substrat olarak bilinen siyah çaydan hazırlanan Kombucha üzerinde yapılmıştır. Siyah çay, çay mantar hücrelerinin gelişimi için gerekli olan yüksek nitrojen kaynaklarına sahip kafein, teofilin gibi pürin türevlerini içermektedir (Reiss 1994; Jayabalan vd., 2007, Essawet vd., 2015). Botanik açıdan bakıldığında, çay bitkileri Camelliasinensis var. sinensis ve Camelliasinensis var. assamica olmak üzere Theaceae familyasına ait iki ana çeşitten oluşur (Hara vd., 1995a). İlk apikal yapraklar toplanır ve farklı yöntemlerle işlenebilir. Yeşil çay ve beyaz çay, enzimleri etkisiz hale getirmek için bir sabitleme aşamasıyla veya bu yöntem kullanılmadan kolayca kurutulur (Hara vd., 1995b), Dünyadaki en popüler form olan siyah çay ise, yaprak polifenollerinin çok 
aşamalı bir enzimatik işlem fermantasyonu ve oksidasyonunun bir sonucudur (Hara vd., 1995c). Bu nedenle, bu çay türleri arasındaki kompozisyon farklılıkları, farklı fermente içeceklere yol açmaktadır. Nitekim, çay çok zengin bir kompleks olarak, 2.000'in üzerinde farklı madde içermektedir (Wheeler ve Wheeler, 2004). Fermantasyon işlemi ile son içecek bileşiminin, birçok bileşenin biyotransformasyonu, salgilanmas1 ve/veya bozunması birkaç modifikasyonuna yol açmaktadır. Dolayısıyla, ortaya çıkan Kombucha metabolik bileşimi, fermantasyon süresinin yanı sıra (oda sıcaklığında; 7 - 10 gün) orijinal substrat ile ilgilidir (Chen ve Liu, 2000). Aktif bileşiklerin belirlenmesi ve içeceğin tutarlı kalitesini tahmin etmek için bu parametrelerin daha nicel araştırmalarla göz önünde bulundurulması gerekir.

Kombucha'nın çeşitli bakterilere karşı antimikrobiyel aktivite gösterdiği ile ilgili çok sayıda bilimsel yayın bulunmaktadır (Greenwalt vd., 1998; Sreeramulu vd., 2001). Kombucha'da mevcut olan bakteri ve mayalar güçlü bir simbiyoz oluşturur ve patojenik bakterilerin büyümesini inhibe edebilir (Liu vd., 1996). Sreeramulu vd. (2001) tarafindan yapılan bir çalışmada, 14 gün boyunca Kombucha mantarı ile fermente edilen siyah çayın, Shigella sonnei, Escherichia coli, Salmonella enteritidis ve Salmonella typhimurium'un büyümesini engelleyebildiği kanıtlanmıştır. Steinkraus vd. (1996) Kombucha çayının Helicobacter pylori, E. coli, Staphylococcus aureus ve Agrobacterium tumefaciens'e karşı antimikrobiyel aktivite gösterdiğini bildirmiş ve bu antimikrobiyel etkiyi çoğunlukla fermantasyon işlemi sırasında üretilen asetik asit ile ilişkilendirmiş̧lerdir. Farklı bir çalışmada Greenwalt vd. (1998), S. aureus, E. coli serotip H10 (patojenik olmayan), E. coli serotip H48 (patojenik), S. typhimurium,
Bacillus cereus ve A. tumefaciens'a karş1, siyah ve yeşil çayların kombuchalarının fermentasyonun dokuzuncu gününde antimikrobiyal potansiyelleri olduğunu bildirmişlerdir. Antimikrobiyel etki üzerinde, fermente içeceğin asetik, laktik ve glukonik asitlerin varlı̆̆ının etkili olduğu öne sürülmektedir (Frank, 1994; Hobbs, 1995). Tietze (1995), antibakteriyel bir madde olan usnik asitin kombucha kültürlerinde varlığını tanımlamışıtır. Daha yakın zamanlarda asetik asidin başlıca antimikrobiyal ajan olduğu öne sürülmüştür (Greenwalt vd. 1998) ve bakteriyosinler ile çaydan türetilmiş fenolik bileşikler gibi diğer bileşikler de antimikrobiyel etkide potansiyel oluşturmaktadır (Sreeramulu vd., 2001). Kombucha'nın antimikrobiyal aktivitesinin sistematik olarak araştırılması, fermentasyon sirasinda üretilen organik asitler veya proteinler (enzimler) dışındaki antimikrobiyal bileşiklerin ve ayrıca çayda orijinal olarak bulunan tanenlerin varlığını ortaya koymuştur (Sreeramulu vd., 2001). Yeşil çay kombucha hazırlanmasında kullanılabilmesine rağmen, içeceklerin antimikrobiyal aktivitesi üzerine yapılan çalışmaların çoğu, en iyi substrat olarak bilinen siyah çaydan hazırlanan kombucha üzerinde gerçekleştirilmiştir (Reiss, 1994; Jayabalan vd., 2007).

Kombucha'nın antioksidan aktivitesi, kanser önleme, bağışıklık arttırma, iltihaplanma ve artriti hafifletmesi gibi iddia edilen faydalı etkileri, içeceğin biyoaktif özellikleri ile ilişkilendirilmektedir. Jayabalan vd. (2008) Yeşil çay, siyah çay ve çay atık malzemelerinden hazırlanan kombucha çayının serbest radikal süpürme kabiliyetleri üzerine etkilerini araştırdıkları çalışmalarında, toplam fenolik bileşiklerin, DPPH radikalinde temizleme aktivitesinin, süperoksit radikalinin ve hidroksil radikal aracılı linoleik aside karşı inhibe edici aktivitenin, 
fermantasyon süresinde bir artış ile arttığını, buna karşın, gücü düşüren hidroksil radikal temizleme kabiliyetinin ve antilipid peroksidasyon kabiliyeti azaldığını bildirmişlerdir. Malbasa vd. (2011) 3 farklı başlangıç kültürünün (karışı asetik bakteri kültürü ve Zygosaccharomyces sp., Karış1k asetik bakteri kültürü ve $S$. cerevisiae, doğal yerel kültür) yeşil çay ve siyah çay kombucha içeceğinin antioksidan aktiviteleri üzerine etkilerini incelemişlerdir. En yüksek antioksidan aktiviteyi doğal yerel kültür ile fermente edilen yeşil çaylarda ve karışık asetik bakteri kültürü ve Zygosaccharomyces sp. ile fermente edilen siyah çay örneklerinde tespit edilmiştir. Kombucha çayının antioksidan özelliği, tersiyer bütil hidroperoksit (TBHP) kaynaklı sitotoksisiteye karşı murin hepatositler kullanılarak test edilmiş ve kombucha çayının TBHP'nin neden olduğu değişiklikleri nötralize ettiği ve hücre ölümünü önlediği gösterilmiştir. Bu karşı etkiler, fermente edilmemiş siyah çay ile de gösterilmiştir, ancak kombucha çayının daha verimli olduğu bulunmuştur (Bhattacharya vd., 2011). Kombucha çayının antioksidan aktivitesi, çay polifenolleri, askorbik asit ve DSL'nin (D-sakarin asidi-1,4lakton) varlığından kaynaklanmaktadır. Kombucha çayının fermente edilmemiş çaydan daha yüksek antioksidan aktivitesine sahip olduğu ve bunun fermantasyon sırasında bakteri ve maya tarafindan üretilen enzimler tarafindan çay polifenollerinin yapısal modifikasyonlar nedeniyle olabileceği gözlemlenmiştir (Jayabalan vd., 2010).

$\mathrm{Bu}$ çalışmada siyah, beyaz ve yeşil çaylardan üretilen Kombuchaların antimikrobiyel, antioksidan etkileri ile duyusal özelliklerinin belirlenmesi amaçlanmıştır.

\section{Materyal ve Metot}

\subsection{Materyal}

$\mathrm{Bu}$ çalışmada materyal olarak kullanılan; Kombucha üretimi için gerekli olan Kombucha kültürü, Canberk Gıda İhtiyaç Mad. Nak. San. ve Tic. Ltd. Şti., (Yenimahalle/ Ankara), çaylar (beyaz, siyah ve yeşil çay) ise Doğadan Gıda Ürünleri San. ve Paz. A.Ş (Akyurt/Ankara) temin edilmiştir. Kombuchaların üretimi ve analizleri Giresun Üniversitesi Gıda Mühendisliği Bölümü laboratuvarlarında gerçekleştirilmiştir.

Kombucha çaylarının antimikrobiyel etkilerinin belirlenmesinde gida ve insan patojeni olan, Gram pozitif ve Gram negatif bakterilerden yararlanılmıştır. Listeria monocytogenes, Staphylococcus aureus (ATCC 25923), Escherichia coli Tip 1, Vibrio parahaemolyticus (ATCC 17802), Bacillus cereus, Salmonella typhimurium, Staphylococcus epidermis, Yersinia pseudotuberculosis, Enterococcus faecalis, Klebsiella pneumoniae ve Proteus vulgaris test mikroorganizmaları olarak kullanılmıştır. Seçici besiyerinde büyütülen her bir koloni, 5 $\mathrm{mL}$ Nutrient Broth (Merck) ortamı içine aşılanmış ve $37^{\circ} \mathrm{C}$ 'de $18-24$ saat inkübasyona bırakılmıştır. İnkübasyon sonrası, $0.5 \mathrm{Mc}$ Farland standardına tekabül eden 1-2x $10^{6}$ $\mathrm{kob} / \mathrm{mL}$ hücre içeren bakteri kültürlerinden stok kültürler hazırlanmıştır.

\subsection{Kombucha çaylarının üretimi}

Farklı çay türlerinden (siyah, beyaz ve yeşil) hem Kombucha ilave edilmiş hem de Kombucha ilave edilmemiş çay üretimi için 3 litre su kaynatılmış ve 30 gram olarak tartımı yapılan çaylar kaynatılmış sıcak su içerisinde yaklaşık 30 dakika boyunca demlenmeye bırakılmıştır. Demlenen çaylar süzülerek, $\% 10$ oranında toz şeker (sakkaroz) ilavesi yapılmış ve karıştırılarak oda sıcaklığına (25 $\left.{ }^{\circ} \mathrm{C}\right)$ kadar soğumaya bırakılmıştır. Oda sıcaklığına getirilen demlenmiş çaylara 
"Kombucha mantarı" piyasada satıldığı hali ile bir bütün olarak ilave edilmiş ve kapların ağzı fermantasyon için gerekli olan oksijen teması için tülbent ile kapatılmıştır. Tüm çay örnekleri 10 gün boyunca oda sıcaklığında fermantasyona bırakılmış, fermantasyon sonunda analizler için $4{ }^{\circ} \mathrm{C}$ 'de depolanmıştır (Chu ve Chen, 2006).

\subsection{Antimikrobiyel aktivite belirlenmesi}

Farklı çay türlerinden hazırlanan Kombuchaların test mikroorganizmalarına karş1 antimikrobiyel etkilerinin belirlenmesinde Disk Difüzyon Yöntemi kullanılmıştır. Analizler için, bakteriyel stok çözeltileri, Mueller Hinton Agar (Merck) besiyerine $100 \mu \mathrm{L}$ olarak aşılanmış ve ortamın yüzeyine steril cam baget ile yayılmıştır. Ekimi yapılan bakteri kültürlerinin kuruması için 15-20 dakika beklenmiştir. Steril koşullarda stok kültürleri ile aşılanan ortam üzerine $6 \mathrm{~mm}$ çapında (Schleicher \& Schül, Nr. 2668, Almanya) steril boş antibiyotik diskler yerleştirilmiştir. Steril boş antibiyotik disklere, 10,20 ve $30 \mu \mathrm{L}$ miktarlarında hazırlanan Kombucha çayları aseptik koşullarda emdirilmiştir. Hazırlanan ortam, bakteri kültürleri için $37{ }^{\circ} \mathrm{C}$ 'de $18-24$ saat boyunca inkübasyona bırakılmıştır. İnkübasyondan sonra meydana gelen inhibisyon zon çapları, milimetre olarak ölçülerek kaydedilmiştir. Karşılaştırma için, antimikrobiyel madde içermeyen boş antimikrobiyel diskler kontrol olarak kullanılmıştır (Engin vd., 2018).

\subsection{Antioksidan aktivitenin belirlenmesi}

$\mathrm{Bu}$ çalışmamızda Kombucha çaylarının radikal yakalama kapasitelerinin değerlendirilmesine dayanan iki antioksidan aktivite tayin yöntemi uygulanmıştır. Kombucha çaylarının antioksidan aktivitesi, oldukça yüksek antioksidatif etkiye sahip yeşil, beyaz ve siyah çaylarla karşılaştırılmıştır. Antioksidan aktivite analiz metodlarından ilki, Re vd. (1999) uyguladığı yöntemin modifiye edilmesiyle gerçekleştirilmiştir. $\mathrm{Bu}$ yönteme göre, antioksidan aktivite tayini analizlerinde öncelikle $2.45 \mathrm{mM}$ potasyum persülfat içeren 7 mM'lık ABTS çözeltisi hazırlanmıştır. Bu çözelti, ortam sıcaklığında karanlıkta en az 16 s bekletilerek, ABTS •+ radikalinin oluşması sağlanmıştır. Analize başlamadan önce ABTS •+ radikal çözeltisinden $1 \mathrm{~mL}$ alınarak $734 \mathrm{~nm}$ 'de absorbans değeri $0.700 \pm 0.05$ olacak şekilde etanol ile seyreltilmiştir. Seyreltilmiş ABTS •+ radikal çözeltisinden 1 mL mikro küvete alınmış, Saf etil alkole karşı karş1 okuma yapmak üzere spektrofotometreye (Hach DR6000, Lange GmbH, 189 Germany) yerleştirilmiş ve başlangıç absorbans değeri belirlenmiştir. Mikro küvet içindeki radikal çözeltisi üzerine örnekten 20-50 $\mu \mathrm{L}$ eklenir eklenmez kronometre çalıştırılmıştır. $6 \mathrm{dk}$ boyunca, her bir dakikada absorbans ölçümü yapılarak sonuçlar kaydedilmiştir. Örneklere uygulanan spektrofotometrik uygulamalar troloks standartlarına da uygulanmış, ortalama inhibisyon değerleri hesaplanarak Troloks konsantrasyonuna karsı grafiğe işlenmiştir. Elde edilen verilere lineer regresyon analizi uygulanmak suretiyle, Troloks standart eğrisine ve bu eğriyi tanımlayan eşitliğe ulaşılmıştır. Sonuçlar Troloks Eşdeğeri antioksidan kapasite (TEAC) (mM TE/ g Kuru örnek) olarak ifade edilmiştir. Farklı Kombucha çay örneklerinin antioksidan aktivitesini belirlemedeki ikinci yöntemde, DPPH radikalini yakalama kabiliyetine dayanılarak ölçüm yapılmıştır (Engin vd., 2018). DPPH (2,2-difenil-1-pikrilhidrazil) serbest radikal yakalama yönteminde, kararlı ve sentetik bir radikal olan DPPH kullanılır ve antioksidanın bu serbest radikali yakalama yeteneği ölçülerek antioksidan aktivite 
tanımlanır. $\mathrm{Bu}$ yönteme göre, belli bir konsantrasyon aralı̆̆ındaki $(20 \mu \mathrm{L}-100 \mu \mathrm{L})$ uygun oranda seyreltilmiş örnek ekstratlarından ve standart madde Trolokstan $0,1 \mathrm{ml}$ alınmış ve üzerine $6 \mathrm{ml}$ tamamlanacak şekilde DPPH etanol solüsyonu $\left(6 \times 10^{-5} \mathrm{M}\right)$ ilave edildikten sonra vortekste karıştırılıp, reaksiyon stabil duruma gelinceye dek oda sıcaklığında, karanlıkta $30 \mathrm{dk}$ bekletilmiştir. DPPH, koyu mor renkte bir radikaldir. Antioksidandan bir proton alarak renksiz $\alpha, \alpha-$ difenil- $\beta$-pikrilhidrazil molekülüne dönüşür. Antioksidan madde tarafindan indirgenmesi sonucu rengi aç1lır. Reaksiyon sonucunda oluşan rengin absorbansı, UV spektrofotometrede (Hach DR6000, Lange GmbH, 189 Germany) 517 nm'de ölçülmüştür. DPPH ve Troloks kalibrasyon eğrisi çizilmiştir. Örneklerinin \% inhibisyon değerleri DPPH kalibrasyon grafiğinden yararlanılarak hesaplanmış ve örneklerin antioksidan aktiviteleri, Troloks eşdeğeri olarak hesaplanmıştır.

\subsection{Duyusal analiz}

Kombucha çayı örneklerinin duyusal analizi, çay ve soğuk içecek tüketimini seven, sigara kullanmayan, Gıda Mühendislerinden oluşan 8 kişilik bir panelist grubu ile gerçekleştirilmiştir. Dokuz puanlık sistem ve 1'den 10'a kadar olan puanlama aralığını değerlendiren betimsel yöntem ile çay örneklerinin aroma, lezzet, parlaklık, dem rengi, burukluk ve genel beğenilirlik özellikleri değerlendirilmiştir (Avcı, 2006).

\section{6. İstatiksel analizler}

Kombucha çayı örneklerinin antimikrobiyel ve antioksidan aktivite ile duyusal analiz sonuçları tesadüf blokları deneme planına göre Windows SPPS 20.0 software istatistik paket programı (SPSS Inc., Chiago, IL, USA) kullanılarak yorumlanmıştır. Araştırma sonuçları tek yönlü varyans analizi kullanılarak değerlendirilmiştir.

\section{Sonuç ve Tartışma}

\subsection{Antimikrobiyel aktivite sonuçları}

Farklı çay türlerinden elde edilen Kombuchaların test mikroorganizmalarına karşı gösterdikleri antimikrobiyel aktivite sonuçları Tablo1'de gösterilmiştir. Tablo1'de görüldüğü üzere, Kombucha çaylarına karşı en dirençli bakteri şusu K. pneumoniae'dır. $B$. cereus, $Y$. pseudotuberculosis, E. faecalis ve $P$. vulgaris diğer dirençli bakteri suşları olarak tespit edilmiştir. Antimikrobiyel analizler sonucunda ise Kombucha çaylarına karşı en hassas bakteri şusunun L. monocytogenes olduğu belirlenmiştir. Antimikrobiyel etki açısından çay türleri kendi aralarında karşılaştırıldıkların da ise test mikroorganizmalarına karşı en yüksek antimikrobiyel etkinin yeşil çay ile hazırlanan Kombuchalar ile sağlandı̆̆ tespit edilmiştir. Buna göre en yüksek zon çapı $(27.00 \pm 7.07$ $\mathrm{mm})$ L. monocytogenes'e karşı yeşil çay ile hazırlanan Kombuchalar ile elde edilmiştir $(p \leq 0.05)$. Bu etkiyi sirasiyla beyaz ve siyah çay ile hazırlanan Kombucha örnekleri takip etmiştir. 
Tablo 1. Kombucha çay örneklerinin test mikroorganizmalarına karşı antimikrobiyel aktiviteleri

\begin{tabular}{|c|c|c|c|c|c|c|c|c|c|}
\hline \multirow[b]{3}{*}{ Mikroorganizma } & \multicolumn{9}{|c|}{ Zon çapları (mm) } \\
\hline & \multicolumn{3}{|c|}{ Kombucha çayı-Siyah } & \multicolumn{3}{|c|}{ Kombucha çayı-Beyaz } & \multicolumn{3}{|c|}{ Kombucha çayı-Yeşil } \\
\hline & $10 \mu \mathrm{l}$ & $20 \mu \mathrm{l}$ & $30 \mu \mathrm{l}$ & $10 \mu \mathrm{l}$ & $20 \mu \mathrm{l}$ & $30 \mu \mathrm{l}$ & $10 \mu \mathrm{l}$ & $20 \mu \mathrm{l}$ & $30 \mu \mathrm{l}$ \\
\hline B. cereus & $\mathrm{ND}^{*}$ & $\mathrm{ND}^{*}$ & $\mathrm{ND}^{*}$ & $\mathrm{ND}^{*}$ & ND* & $\mathrm{ND}^{*}$ & $\mathrm{ND}^{*}$ & $8.50 \pm 0.70^{\mathrm{a}}$ & $10.50 \pm 0.70^{\mathrm{b}}$ \\
\hline E. coli & $\mathrm{ND}^{*}$ & $9.50 \pm 0.70^{\mathrm{a}}$ & $11.00 \pm 1.41^{\mathrm{b}}$ & $\mathrm{ND}^{*}$ & $\mathrm{ND}^{*}$ & $9.00 \pm 1.41^{\mathrm{a}}$ & $\mathrm{ND}^{*}$ & $10.50 \pm 0.70^{\mathrm{a}}$ & $13.00 \pm 0.00^{\mathrm{b}}$ \\
\hline S. aureus & $7.50 \pm 2.12^{\mathrm{a}}$ & $10.50 \pm 0.70^{\mathrm{b}}$ & $12.50 \pm 0.70 \mathrm{c}$ & $\mathrm{ND}^{*}$ & $9.00 \pm 0.00^{\mathrm{a}}$ & $12.50 \pm 0.70^{\mathrm{b}}$ & $\mathrm{ND}^{*}$ & $10.00 \pm 0.00^{\mathrm{a}}$ & $11.00 \pm 1.41^{\mathrm{sb}}$ \\
\hline S. epidermis & $\mathrm{ND}^{*}$ & $8.50 \pm 0.70^{\mathrm{a}}$ & $9.00 \pm 0.00^{\mathrm{ab}}$ & $\mathrm{ND}^{*}$ & $\mathrm{ND}^{*}$ & $10.00 \pm 1.41^{\mathrm{a}}$ & $\mathrm{ND}^{*}$ & $11.00 \pm 0.00^{\mathrm{a}}$ & $13.00 \pm 0.00^{\mathrm{b}}$ \\
\hline V. parahemolyticus & $\mathrm{ND}^{*}$ & $8.00 \pm 0.00^{\mathrm{a}}$ & $10.00 \pm 0.00^{\mathrm{b}}$ & $8.50 \pm 0.70^{\mathrm{a}}$ & $10.50 \pm 0.70^{\mathrm{b}}$ & $12.50 \pm 0.70^{\mathrm{c}}$ & $\mathrm{ND}^{*}$ & $\mathrm{ND}^{*}$ & $12.00 \pm 0.00^{\mathrm{a}}$ \\
\hline Y.pseudotuberculosis & $\mathrm{ND}^{*}$ & $\mathrm{ND}^{*}$ & ND* & $\mathrm{ND}^{*}$ & $10.00 \pm 0.00^{\mathrm{a}}$ & $11.00 \pm 0.00^{\mathrm{ab}}$ & $\mathrm{ND}^{*}$ & $9.50 \pm 0.70^{\mathrm{a}}$ & $11.50 \pm 0.70^{\mathrm{b}}$ \\
\hline L. monocytogenes & $7.00 \pm 0.00^{\mathrm{a}}$ & $10.00 \pm 0.00^{\mathrm{b}}$ & $10.00 \pm 0.00^{\mathrm{b}}$ & $7.50 \pm 0.70^{\mathrm{a}}$ & $9.00 \pm 1.41^{\mathrm{b}}$ & $11.50 \pm 0.70^{\mathrm{c}}$ & $\mathrm{ND}^{*}$ & $16.50 \pm 6.36^{\mathrm{a}}$ & $27.00 \pm 7.07^{\mathrm{b}}$ \\
\hline E. faecalis & $\mathrm{ND}^{*}$ & ND* & ND* & $\mathrm{ND}^{*}$ & $7.00 \pm 0.00^{\mathrm{a}}$ & $10.00 \pm 0.00^{\mathrm{b}}$ & ND* & $\mathrm{ND}^{*}$ & $\mathrm{ND}^{*}$ \\
\hline S. Typhimurium & $\mathrm{ND}^{*}$ & $10.00 \pm 4.24^{\mathrm{a}}$ & $11.50 \pm 3.53^{\mathrm{b}}$ & $\mathrm{ND}^{*}$ & $8.00 \pm 0.00^{\mathrm{a}}$ & $10.00 \pm 0.00^{\mathrm{b}}$ & $9.00 \pm 1.41^{\mathrm{a}}$ & $12.00 \pm 2.82^{\mathrm{b}}$ & $14.00 \pm 2.82^{\mathrm{c}}$ \\
\hline K. pneumoniae & $\mathrm{ND}^{*}$ & $\mathrm{ND}^{*}$ & $\mathrm{ND}^{*}$ & $\mathrm{ND}^{*}$ & $\mathrm{ND}^{*}$ & $\mathrm{ND}^{*}$ & $\mathrm{ND}^{*}$ & $\mathrm{ND}^{*}$ & $\mathrm{ND}^{*}$ \\
\hline P. vulgaris & $\mathrm{ND}^{*}$ & $\mathrm{ND}^{*}$ & $11.00 \pm 1.41^{\mathrm{a}}$ & $\mathrm{ND}^{*}$ & $\mathrm{ND}^{*}$ & $11.00 \pm 1.41^{\mathrm{a}}$ & $\mathrm{ND}^{*}$ & $\mathrm{ND}^{*}$ & $9.50 \pm 0.70^{\mathrm{a}}$ \\
\hline
\end{tabular}

Çalışmamıza benzer olarak Sreeramulu vd. (2000) tarafindan Kombucha'nın antimikrobiyel etkisi birçok patojen mikroorganizmaya karşı test edilmiştir. Araştırma sonuçlarına göre $S$. aureus, $S$. sonnei, E. coli, A. hydrophila, Y. enterolitica, P. aeruginosa, E. kloak, S. epidermis, C. jejuni, S. enteritidis, S. Typhimurium, $B$. cereus, $H$. pylori ve L. monocytogenes'in Kombucha'ya karşı duyarlı olduğu tespit edilmiştir. Kombucha ile ilgili literatürlere göre, test edilen bir dizi patojen bakteriye karş1 inhibisyondan asetik asitin sorumlu olduğu düşünülmektedir (Greenwalt vd., 1998; Sreeramulu vd., 2000; Steinkraus vd., 1996). Asetik asit, mikroorganizmaların hücre zarlarına geçerek bakteriyel hücre ölümüne yol açar (Gökırmaklı vd., 2019). Yapılan bir araştırmada, asetik asitin hücre duvarı yapısını bozması ve hücre içinde ATP kaybına sebep olması neticesinde antimikrobiyel etki gösterdiği tespit edilmiştir. Asetik asidin antimikrobiyel etkisi ise asit iyonlaşma sabiti (Ka) derecesine, ortamın $\mathrm{pH}$ ve sicaklik seviyesine, kullanılan diğer antimikrobiyel ajanlara ve hedef patojenin türüne göre değişebilmektedir (Ayhan ve Bilici, 2015). Bununla birlikte, Sreeramulu vd. (2000, 2001), Kombucha'nın nötr pH'da ve
Kombucha'nın termal denatürasyonundan sonra bile, E. coli, S. sonnei, S. Typhimurium, $S$. enteritidis ve $C$. jejuni'ye karşı antimikrobiyal faaliyetler gerçekleştirdiğini bulmuştur. Bu bulgu, Kombucha'da asetik asit veya büyük proteinler dişındaki antimikrobiyal bileşiklerin varlığını göstermektedir. Sreeramulu vd. (2001) ayrıca Kombucha'daki antimikrobiyal bileşikleri karakterize etmişlerdir. 14 günlük fermantasyon işlemi boyunca, her iki günde bir Kombucha'daki metabolitler analiz edilerek, fermantasyon süresi ile asetik asit ve glukonik asit seviyelerinin arttı̆̆ tespit edilmiştir. Laktik asit veya etanol ise saptanmamıştır. Kombucha'nın antimikrobiyal aktivitesi üzerine yapilan çalışmalar, fermantasyon sırasında üretilen organik asitler veya proteinler (enzimler) dışında, çay örneklerinde bulunan tanenlerin varlığının da etkili olduğunu ortaya koymuştur. Antimikrobiyal bileşenlerin sinerjistik aktivitesi ve organik asitlerin artmasına bağlı olarak düşük $\mathrm{pH}$, muhtemelen Kombucha'nın inhibe edici etkisini güçlendirmiştir (Mo vd., 2008). Chou vd. (1999) farklı Kombucha türlerinin B. subtilis, E. coli, $P$. vulgaris, $P$. fluorescens ve Salmonella spp.'ye karşı antimikrobiyel 
etkilerini araştırmış ve çalışma sonuçlarımıza benzer olarak, alt1 test mikroorganizması arasinda $P$. fluorescens, ekstraktlara en duyarlı iken, $B$. subtilis'in en düşük hassasiyete sahip olduğu tespit edilmiştir. Antimikrobiyal aktivitelerin, farklı fermantasyon derecelerine sahip çay ekstrelerinin test edilen mikroorganizmalara göre değiştiği görülmüştür. Yeşil çay (fermente edilmemiş veya oksitlenmemiş çay) örnekleri en güçlü antimikrobiyal aktiviteyi gösterirken, Longjing, Tieh-Kuan-Ying, Paochung ve oolong gibi kismen fermente edilmiş çay ürünleri, yeşil çayın antimikrobiyel etkisini takip etmiştir. Öte yandan, siyah çay (tamamen fermente edilmiş, okside olmuş) örnekleri en az antimikrobiyal aktivite göstermiştir. $\mathrm{Bu}$ durum, mikrobiyal çay fermantasyonunda yer alan çay mantarının, fermente edilmemiş veya yeşil çay yapraklarında başlangıçta mevcut olan çay kateşinleri veya polifenoller dışındaki antimikrobiyal metabolitlerin oluşumuna katkıda bulunma olasılığını olduğunu göstermektedir (Mo vd., 2005). Bilindiği üzere, çay polifenolleri, özellikle kateşinler, insan sağlığı üzerinde olumlu etkileri olan güçlü antimikrobiyal ve antioksidan etkilere sahiptir (Salman ve Özdemir, 2018). Almajano vd. (2008) yaptıkları bir çalışmada 13 farklı çay çeşidinden elde edilen kateşin infüzyonlarının antimikrobiyal ve antioksidan etkilerini incelemiştir. Gözlenen en yüksek serbest radikal süpürücü aktiviteyi beyaz ve yeşil çayın sağladığı belirlenmiştir. Antimikrobiyal aktivitede ise birkaç mikroorganizma üzerinde yine beyaz ve yeşil çay benzer özellikleri göstermiştir.

\subsection{Antioksidan aktivite sonuçları}

Çeşitli Kombucha çay örneklerinin ABTS ve DPPH radikal süpürme kapasiteleri Tablo 2'de gösterilmiştir. Daha önce yapılan birçok çalışmada yeşil, beyaz ve siyah çayların antioksidan aktivitelerinin oldukça yüksek olduğu belirlenmiştir (Malbasa vd., 2011). Çalışmamızdaki deneme deseninin oluşturulmasındaki ana düşünce, fermantasyon sonucu üretilen farklı Kombuchaların demleme sonucu elde edilen bu çay örnekleri ile kıyaslandığında daha yüksek bir antioksidan aktiviteye sahip olup olmadıklarının ölçülmesidir. Fermantasyon yoluyla elde edilen Kombucha çay örneklerinin ABTS ve DPPH radikal süpürme değerleri incelenmesi sonucu beklenilen bulgulara ulaşılmıştır. Çünkü Kombucha kültürünün var olandan daha yüksek antioksidan özellikli içecek ürettiği belirlenmiştir. Diğer çalışmalara benzer olarak, farklı çay türlerinden hazırlanan fermente Kombucha çaylarının, nötralize çay örneklerine kıyasla daha yüksek antioksidan aktive göstermelerinin, asetik asit içeriğine bağlı olduğunu göstermektedir (Malbasa vd., 2011; Pauline vd., 2016). 
Tablo 2. Kombucha çay örneklerinin antioksidan aktiviteleri

\begin{tabular}{lll}
\hline Çay Örnekleri & $\begin{array}{l}\text { ABTS (mM Troloks } \\
\text { eşdeğeri/ } \mathbf{g} \text { KM) }\end{array}$ & $\begin{array}{l}\text { DPPH (mM Troloks } \\
\text { eşdeğeri/g KM) }\end{array}$ \\
\hline Yeşil Çay & $13.212 \pm 0.63^{\mathrm{a}}$ & $4.434 \pm 0,27^{\mathrm{a}}$ \\
Kombuçya Çayı-Yeşil & $14.993 \pm 0,52^{\mathrm{b}}$ & $4.981 \pm 0,31^{\mathrm{ab}}$ \\
\hline Beyaz Çay & $7.402 \pm 0,39^{\mathrm{a}}$ & $2.467 \pm 0,16^{\mathrm{a}}$ \\
Kombuçya Çayı-Beyaz & $8.773 \pm 0,41^{\mathrm{b}}$ & $2.953 \pm 0,23^{\mathrm{ab}}$ \\
\hline Siyah Çay & $3.426 \pm 0,29^{\mathrm{a}}$ & $1.161 \pm 0,18^{\mathrm{a}}$ \\
Kombuçya Çayı-Siyah & $4.845 \pm 0,23^{\mathrm{b}}$ & $1.623 \pm 0,22^{\mathrm{b}}$ \\
\hline
\end{tabular}

*a-b: Aynı sutundaki farklı üst simgeler $\mathrm{p} \leq 0.05$ seviyesinde önemli bir fark olduğunu gösterir.

\subsection{Duyusal analiz sonuçları}

Farklı çay türleri ile üretilen Kombucha çaylarının aroma, lezzet, parlaklık, dem rengi, burukluk ve genel beğenilirlik duyusal özellikleri Şekil 1'de gösterilmiştir. aldığı tespit edilmiştir. Örnekler lezzet açısından değerlendirildiğinde siyah çay ile hazırlanan kombuchaların (7.62) en beğenilen örnekler olduğu, beyaz çay örneklerinin ise en düşük puanı (5.62) aldığı görülmüştür.

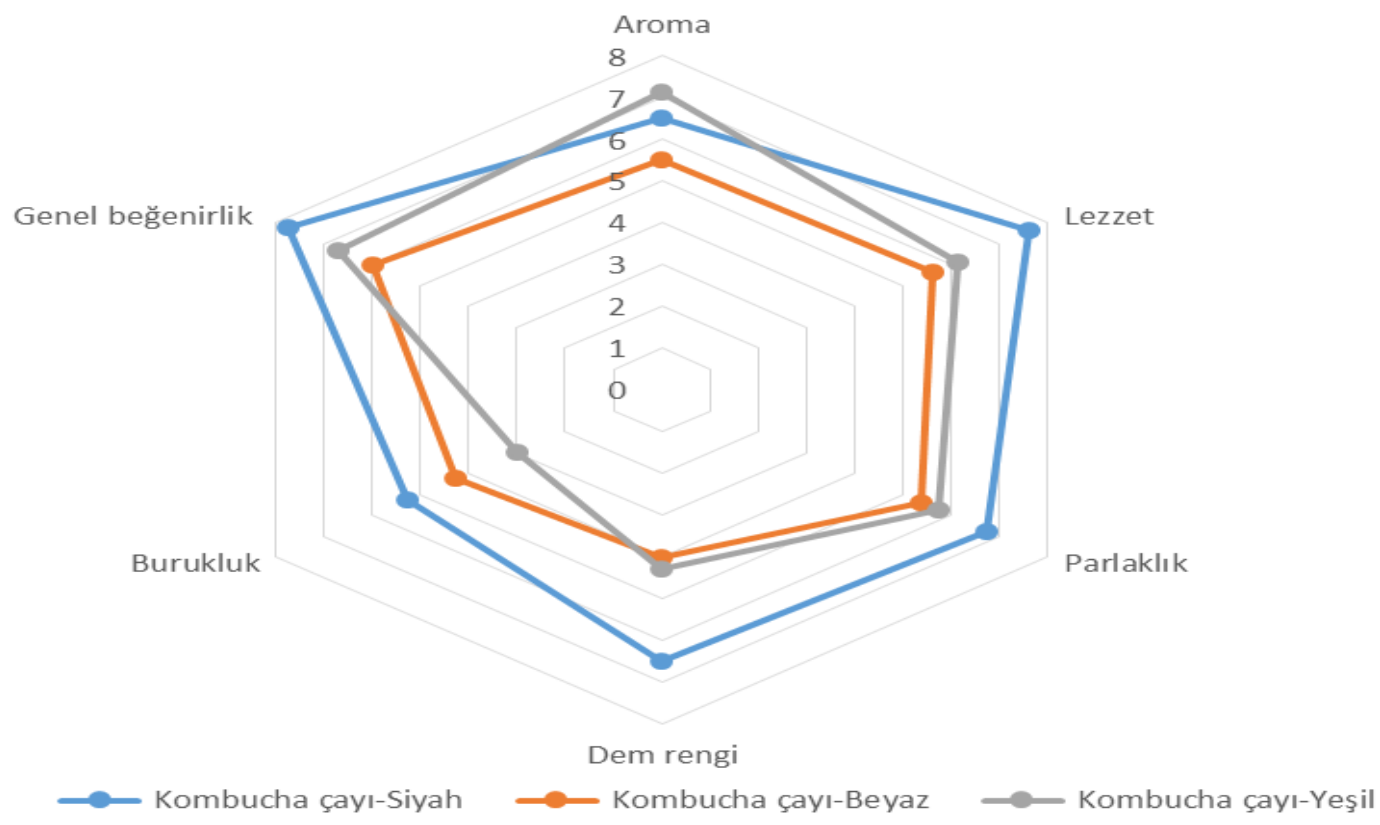

Şekil 1.Kombucha çaylarının duyusal analizi

Kombucha çay örneklerinin aroma özellikleri değerlendirildiğinde, Șekil 3'de de görüldüğü gibi aroma açısından en beğenilen çay örneklerinin yeşil çay ile hazırlanan çay örnekleri (7.14) olduğu tespit edilmiş iken, en düşük puanı ise beyaz çay örneklerinin (5.50)
Panelistler parlaklık açısından çay örneklerini değerlendirdiklerinde en bulanık örneklerin (5.37) beyaz çay örneklerinin olduğunu, en parlak örneklerin ise (6.75) siyah çay örneklerinin olduğunu belirtmişlerdir. Dem rengi açısından değerlendirme yapıldığında, 
beklenildiği gibi en koyu dem rengine siyah çay örneklerinin (6.50), en açık dem rengi sonuçlarına (4.00) ise beyaz çay örneklerinin sahip olduğu tespit edilmiştir. Çay örnekleri burukluk açısından incelendiğinde çay örneklerinin yüksek burukluk değerlerine sahip olmadığını, siyah çay örneklerini en buruk çay örnekleri (5.25) olarak, beyaz çay örneklerini ise burukluk değeri en düşük (3.00) olan örnekler olarak belirtilmiştir. Fenolik bileşiklerin çayın başlıca kalite parametrelerinden biri olduğu bilinmektedir (Yao vd., 2004; Borse vd., 2002). Klorojenik asit, kateşinler ve bunların türevleri çayın tadı (acılık ve burukluk gibi) üzerine etkili olmaktadır (Goto, 1996). Siyah çaylar genel olarak daha yüksek oranda fenolik madde içermeleri nedeniyle daha yüksek burukluk değerlerine sahip Kombucha cayı elde edilmiştir (Cavlak ve Yağmur, 2016). Genel beğenilirlik açısından tüm çay örnekleri içerisinde en yüksek puanı (7.75) siyah çay ile hazırlanan Kombucha çayları almış iken, en düşük puanı 6.70 ile yeşil çay ile hazırlanan Kombucha çayları almıştır. Genel olarak tüm çay örnekleri beğenilerek tüketilmiştir.

Sonuç olarak, fermente bir içecek olarak Kombucha çayları sahip oldukları antimikrobiyel ve antioksidan özellikleri nedeniyle fonksiyonel bir içecektir. Literatür çalışmaları incelendiğinde çalışmaların özellikle siyah ve yeşil çaydan elde edilen Kombuchalar üzerinde yoğunlaştığ görülmektedir. Bu açıdan çalışmamızda beyaz çay örneklerine de yer vererek değerlendirmelerde bulunulmuştur. Literatür çalışmalardan farklı olarak duyusal özellikleri ve tüketici beğenilirlikleri değerlendirilen Kombucha çay örneklerinin tüketiciler tarafindan tercih edilen bir ürün olduğu tespit edilmiştir. Çay üretimi ve tüketimin Avrupa Birliği ülkelerine kıyasla oldukça fazla olduğu ülkemizde, alternatif bir içecek olarak
Kombucha çaylarının özelliklerinin araştırılmasının önemli olduğu düşünülmektedir. Çalışma bulgularının Kombuchaların tanınırlığına katkı sağlayacağı ve ileriki çalışmalarda faydalı olacağı düşünülmektedir.

\section{Kaynaklar}

Aidoo, K.E., Nout, M.J.R., Sarkar, P.K. 2006. "Occurrence and Function of Yeasts in Asian Indigenous Fermented Foods", FEMS Yeast Res., 6(1), 30-39.

Anken, R.H., Kappel, T. 1992."Histochemical and Anatomical Observations Upon The Tea Fungus", Eur.Arch.Biol., 103, 219-222.

Avc1, N. 2006. "Mikrodalga teknolojisi ile üretilen yeşil ve siyah çaylarda toplam antioksidan aktivitesi ve fenolik madde miktarlarının incelenmesi" ,Yüksek Lisans Tezi, İstanbul Teknik Üniversitesi Fen Bilimler Enstitüsü, İstanbul.

Almajano, M.P., Carbó, R., Jiménez, J.A.L., Gordon, M.H. 2008. "Antioxidant and antimicrobial activities of tea infusions", Food Chem., 108(1), 55-63.

Ayhan, B., Bilici, S. 2015. "Toplu beslenme sistemlerinde kullanılan gida dezenfektanları ", Türk Hij.ve Deneysel Biy., 72(4), 323-336.

Balentine, D.A., Wiseman, S.A., Bouwens, L.C. 1997. "The Chemistry of Tea Flavonoids", Crit. Rev. FoodSci. Nutr., 37, 693-704.

Bauer-Petrovska, B., Petrushevska-Tozi, L. 2000. "Mineral and water soluble vitamin content in the Kombucha drink", J. Food Sci. Technol., 35, 201-205.

Bhattacharya, S., Manna, P., Gachhui, R., Sil, P.C. 2011. "Protective effect of Kampucha tea against tertiary butylhydroperoxide-induced cytotoxicity and cell death in murine hepatocytes", Indian J Exp Biol., 49,511-524. 
Borse, B.B., Rao, L.J.M., Nagalakshmi, S., Krishnamurthy N. 2002. "Fingerprint of black teas from India: identification of the regio-specific characteristics", Food Chem., 79, 419-424.

Cavlak, S., Yağmur, C. 2016. "Bazı poşet çayların toplam fenolik madde ve antioksidan aktivitelerinin belirlenmesi". Ç. Ü. Fen ve Müh. Bil. Derg., 34 (4), 11-19.

Chen, C., Liu, B.Y. 2000. "Changes in Major Components of Tea Fungus Metabolites During Prolonged Fermentation", J. Appl. Microbiol., 89(5), 834-839.

Chou, C.C., Lin, L.L., Chung, K.T. 1999. "Antimicrobial Activity of Tea as Affected By The Degree of Fermentation and Manufacturing Season", Int. J. Food Microbiol., 48(2), 125-130.

Chu, S.C.,Chen, C. 2006. "Effects of Origins and Fermentation Time on The Antioxidant Activities of Kombucha", Food Chem., 98, 502-507.

Dufresne, C., Farnworth, E. 2000. "Tea, Kombucha, and Health: A Review", Food Res. Int., 33, 409-421.

El-Taher, E.M. 2011. "Kombucha: A New Microbial Phenomenon and Industrial Benefits", Afr. J.Biol.Sci., 7, 41-60.

Engin, M.S., Kalkan, S., Çay, S., Güder, A., Otağ, M.R., Gür, G., Kablan, A. 2018. "DPPH Radical Scavenging, Phenolic and Antimicrobial Activity of Momordica charantia and Rheum ribes", Research Journal of Pharmaceutical, Biological and Chemical Sciences, 9(4), 447-458.

Ernst, E. 2003. "Kombucha: A Systematic Review of The Clinical Evidence", Complementary Med. Res., 10(2), 85-87.

Essawet, N.A., Cvetkovic, D., Velicanski, A., Canadanovic-Brunet, J., Vulic, J., Maksimovic, V., Markov, S. 2015. "Polyphenols and Antioxidant Activities of
Kombucha Beverage Enriched with Coffee berry Extract", Chem. Ind. Chem. Eng. Q.,21 (3), 399-409.

Frank, G.W. (1994) "Kombucha: Healthy Beverage and Natural Remedy from the Far East, 4th ed. Wilhelm Ennsthaler: Steyr, Austria

Greenwalt, C.J., Steinkraus, K.H., Ledford, R.A. 1998. "Determination and Characterization of The Antimicrobial Activity of The Fermented Tea Kombucha, Lebensm Wiss Technol., 13, 291-296.

Greenwalt CJ, Steinkraus KH, Ledford RA 2000. "Kombucha, The Fermented Tea: Microbiology, Composition, and Claimed Health Effects", J. Food Protect., 63(7), 976981.

Goto, T., Yoshida, Y., Kiso, M., Nagashima, H., 1996. "Simultaneous analysis of individual catechins and caffeine in green tea", J. of Chromatography A, 749, 295-299.

Gökırmaklı, Ç., Budak, H. N., Güzel-Seydim, Z. B. 2019. "Antimicrobial Effect of Vinegar", Turkish J of Agriculture-Food Sci and Tech., 7(10), 1635-1640.

Hara, Y., Luo, S.J., Wickremashinghe, R.L., Yamanishi, T. 1995a. "Botany (of Tea)", Food Rev. Int., 11, 371-374.

Hara, Y., Luo, S.J., Wickremashinghe, R.L., Yamanishi, T. 1995b. "IV. Processing Tea", Food Rev. Int., 11, 409-434.

Hara, Y., Luo, S.J., Wickremashinghe, R.L., Yamanishi, T. 1995c. "V. Chemical Composition of Tea", Food Rev. Int., 11, 435456.

Hartmann, A.M., Burleson, L.E., Holmes, A.K., Geist, C.R. 2000. "Effects of Chronic Kombucha Ingestion on Open-Field Behaviors, Longevity, Appetitive Behaviors, and Organs in C57-BL/6 Mice: A Pilot Study", Nutrition, 16 (9), 755-761. 
Hobbs, C. (1995). "Kombucha Manchurian Tea Mushroom: The Essential Guide", Botanica Press, Santa Cruz, CA.

Jankovic, I., Stojanovic, M. 1994. "Microbial and Chemical Composition, Growth, Therapeutical and Antimicrobial Characteristics of Tea Fungus", Mikrobiologija, 33, 25-34.

Jayabalan, R., Marimuthu, S., Swaminathan, K. 2007. "Changes in Content of Organic Acid and Tea Polyphenols During Kombucha Tea Fermentation", Food Chem. 102, 392398.

Jayabalan, R., Subathradevi, P., Marimuthu, S., Sathishkumar, M., Swaminathan, K. 2008. "Changes in free radical scavenging ability of Kombucha tea during fermentation", Food Chem, 109, 227-34.

Jayabalan, R., Malini, K., Sathishkumar, M., Swaminathan, K., Yun, S.E. 2010. "Biochemical characteristics of tea fungus produced during kombucha fermentation", Food Sci Biotechnol., 19, 843-847.

Kappel, T., Anken, R.H. 1993. "The TeaMashroom”, Mycologist, 7(1), 12-13.

Liu, C.H.,Hsu, W.H., Lee, F.L., Liao, C.C.1996. "The Isolation and Identification of Microbes From a Fermented Tea Beverage, Haipao, and Their Interactions During Haipao Fermentation", Food Microbiol., 13, 407-415.

Malbasa, R.V., Loncar, E.S., Vitas, J.S., Canadanovic-Brunet, J.M. 2011. "Influence of Starter Cultures on The Antioxidant Activity of Kombucha Beverage", Food Chem.,127, 1727-1731.

Mayser, P., Fromme, S., Leitzmann, C., Grunder, K. 1995. "The Yeast Spectrum of Tea Fungus Kombucha", Mycodes, 38, 28995.

Mo, H.Z., Xu, X.Q., Yan, M.C., Zhu, Y. 2005. "Microbiological Analysis and Antibacterial Effects of The Indigenous Fermented Puer
Tea", Agro Food Industry Hi-Tech., 16(6), 1618.

Pauline, T., Dipti, P., Anju, B., Kavimani, S., Sharma, S.K., Kain, A.K., Sarada, S.K., Sairam, M., Pure, A.E., Pure, M.E. 2016. "Antioxidant and Antibacterial Activity of Kombucha Beverages Prepare during Banana Peel, Common Nettles and Black Tea Infusions", Appl. Food Biotechnol., 3(2), 125130.

Ram, M.S.,Anju, B., Pauline, T., Prasad, D., Kain, A.K., Mongia, S.S., Sharma, S.K., Singh, B., Singh, R., Ilavazhagan, G., Kumar, D., Selvamurthy, W., 2000. "Effect of Kombucha tea on chromate (VI)-induced oxidative stress in albino rats", $J$. Ethnopharmacol., 71, 235-240.

Re, R., Pellegrini, N., Proteggente, A., Pannala, A., Yang, M., Rice-Evans, C. 1999. "Antioxidant activity applying an improved ABTS radical cation decolorization assay", Free Radic. Biol. Med., 26(9-10), 1231-1237.

Reiss, J. 1994. "Influence of Different Sugars on The Metabolism of The Tea Fungus", $Z$. Lebensm. Unters. Forsch., 198, 258-261.

Salman, S., Özdemir, F. 2018. "Beyaz Çay: Üretimi, Bileşimi ve Sağlık Üzerine Etkileri”, Akademik Glda, 16(2), 218-223.

Sreeramulu, G., Zhu, Y., Knol, W. 2000. "Kinetic Study on Kombucha Fermentation and Preliminary Investigations on Its Antimicrobial Activity", J. Agric. Food Chem., 48, 2589-2594.

Sreeramulu, G., Zhu,Y., Knol, W. 2001. "Characterization of Antimicrobial Activity in Kombucha Fermentation", Acta Biotechnol., 21, 49-56.

Steinkraus, K.H., Shapiro, K.H., Hotchkiss, J.H., Mortlock, R.P. 1996. "Investigations Into The Antibiotic Activity of Tea Fungus / Kombucha Beverage", Acta Biotechnol., 16: 199-205. 
Teoh, A.L., Heard, G., Cox, J. 2004. "Yeast Ecology of Kombucha Fermentation”, Int. J. Food Microbiol., 95, 119-126.

Tietze, H.W. (1995). "Kombucha: The Miracle Fungus", 6th Ed., Phree Books, Bermgui, Australia. 72

Wheeler, D.S., Wheeler, W.J. 2004. "The Medicinal Chemistry of Tea", Drug Dev. Res., 61: 45-65.

Yao, L., Jiang, Y., Datta, N., Singanusong, R., Liu, X., Duan, J., 2004. "HPLC analyses of flavanols and phenolic acids in the fresh young shoots of tea (Camellia sinensis) grown in Australia", Food Chem., 84, 253-263. 